\title{
Anti-obesity effect of an isoflavone fatty acid ester on obese mice induced by high fat diet and its potential mechanism
}

\author{
Yao Yao ${ }^{1}$, Xiao-Bo Li², Wei Zhao³, Yan-Yan Zeng ${ }^{1}$, Hong Shen ${ }^{1}$, Hua Xiang³ and Hong Xiao*1
}

\begin{abstract}
Background: The novel compound $\mathbf{1} \mathbf{a}$ is one of the isoflavone fatty acid esters. In order to investigate the anti-obesity effect of compound $\mathbf{1} \mathbf{a}$ and its potential mechanism of influence in adipocyte differentiation, Obese male C57BL/6J mice induced by high-fat diet (HFD) and rat preadipocytes (3T3-L1 cell) were used.

Methods: After 4-week HFD induction, the obese model was made successfully. After treatment with compound $\mathbf{1 a}$, mice plasma biochemistry parameters were analyzed. In addition, mice hepatic tissue slice was observed. In in vitro research, 3T3-L1 cell differentiation by Oil-Red-O staining and adipocyte apoptosis was detected by flow cytometry.

Results: The in vivo results implied that compound $\mathbf{1 a}$ significantly decreased the body weight, white adipose tissue weight of obesity mice $(p<0.05)$, reduced leptin and TG in plasma $(p<0.05)$, elevated HDL-C in serum $(p<0.05)$. The in vitro results suggested that compound $\mathbf{1}$ a could significantly suppress the adipocyte viability and lipid accumulation in the differentiation of preadipocyte, and induce apoptosis in both preadipocytes and mature adipocytes $(p<0.05)$.

Conclusion: Compound $1 \mathbf{a}$ regulates serum lipid profiles, decreases adipose tissue mass and body weight gain by inducing adipocyte apoptosis in high fat diet induced mice. Thus, it may be used to treat obese patients with hypercholesterolemia and hypertriglyceridemia.
\end{abstract}

\section{Background}

Obesity, which results from a prolonged energy imbalance during which intake exceeds expenditure, is a rapidly growing epidemic in modernized world [1] and is a major risk factor for several serious chronic diseases, such as type 2 diabetes, cardiovascular disease, hypertension, stroke, asthma, and certain forms of cancer [2]. Considerable effort has been devoted to the discovery of anti-obesity drugs worldwide. Though there are dozens of potential targets for anti-obesity, only three agents, sibutramine (Reductil ${ }^{\circ}$ or Meridia ${ }^{\circ}$ ), an appetite suppressant orlistat $\left(\mathrm{Xenical}^{\circ}\right)$, an inhibitor of fat absorption and rimonaban, a CB1 antagonist, have been introduced into the market during recent years [3]. But several serious adverse effects of sibutramine, orlistat and rimonaban were reported in clinical practice, including gastrointestinal adverse effect and significant unfavorable effects on

\footnotetext{
* Correspondence: xhnkyy123@yahoo.cn

1 Nanjing Brain Hospital affiliated to Nanjing Medical University, Nanjing 210029, PR China

Full list of author information is available at the end of the article
}

cardiovascular system [4-6]. The difficulty to lose excessive weight is tightly linked to the complexity and redundancy within lipid systems, which involve an intricate network of peripheral signals and neuronal circuits, constitute obstacles to seek effective potential targets for anti-obesity treatments [7]. In the peripheral organizations, the fat tissue plays an important role in maintaining the energy balance. It is not only an energy storage organ, but also a secretion one. It produces and secretes dozens of factors such as leptin, adiponectin, resistin, visfatin, tumor necrosis factor- $\alpha$ (TNF- $\alpha$ ), and interleukin-6 (IL6), which participate in the energy metabolism of adipose tissue itself and the whole body either in an auto/paracrine or an endocrine fashion [8-11]. Obesity is characterized by an increase in the number and size of adipocytes differentiated from fibloblastic preadipocytes in adipose tissues [12].

Adipocytes play a vital role in regulating adipose mass and obesity, in relation not only to lipid homeostasis and energy balance but also to secreting transcription factors 
[13]. 3T3-L1 cells have been served as well-established in vitro model to assess adipogenesis and adipocyte differentiation [14]. The programmed differentiation of preadipocytes into adipocytes involves several stages related to obesity [15]. For these reasons, many research efforts have been conducted in 3T3-L1 cells to search for new health benefit foods/agents for obesity or weight control. Potential therapeutic agents that inhibit adipogenesis or increase adipocyte death by apoptosis could be important tools in preventing obesity [16].

Isoflavones are found at high levels in soy plants and structurally similar to estrogens [17]. They are suggested to be a potential alternative to estrogen therapy in the treatment and prevention of menopausal symptoms, osteoporosis, breast cancer and cardiovascular disease. Genistein, daidzein, glycitein, formononetin and biochanin A are considered to be the most important and hence most studied isoflavone phytoestrogens $[18,19]$. It is also reported that isoflavones have healthful benefits in human obesity and have a positive influence on plasma cholesterol [20].

Here in this paper we defined 4'-methoxy daidzein-7fatty acid esters as compound 1a (Fig.1).

We performed research to evaluate the anti- dyslipidemia effect of compound 1a and its potential mechanism in adipocyte differentiation.

\section{Materials and methods Material}

Compound 1a was provided by China pharmaceutical university. Dulbecco's modified Eagle's medium (DMEM), fetal bovine serum (FBS) were purchased from Gibco BRL of Invitrogen Corporation (Carlsbad, CA). Methylisobutylxanthine, hochest 33342 dye, MTT and Oil-Red-O were obtained from Sigma (St. Louis, MO). Dexamethasone was purchased from Xianju Pharmaceutical Co.Ltd (Zhejiang, China). Insulin was purchased from Wanbang Pharmaceutical Co.Ltd (Xuzhou, China). Leptin ELISA kit was obtained from Boster (Wuhan, China). Anannexin V-fluorescein isothiocyanate (FITC) Apoptosis kit was provided by KeyGene (Nanjing, China). All other reagents were of analytical grade.

\section{Animals and diets}

Fifty male C57BL/6J mice initially weighing $16.03 \pm 1.22 \mathrm{~g}$ from Nanjing University Animal Center were used. The

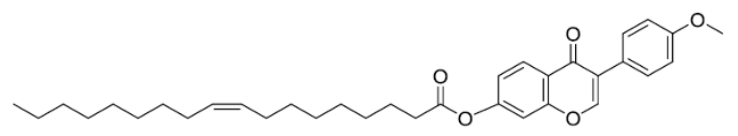

Figure 1 Structural formula of compound $1 \mathrm{a}$. animals were housed in $12 \mathrm{~h}$ light/dark cycle (light on 7a.m.), temperature $22^{\circ} \mathrm{C}$, and allowed adlibitum access to diet and water.

\section{Animal groups}

After one week's acclimatization period, 50 mice were divided randomly into two groups: the normal group $(\mathrm{n}=$ 10) were fed with low fat diet (LFD), whereas the experimental group $(\mathrm{n}=40)$ were fed with high-fat diet (HFD).

After 4-week induction, the obese model was made successfully. The 40 obese mice were divided into four groups $(\mathrm{n}=10 /$ each group): model group, low dosage group (50 mg.kg-1 compound 1a), high dosage group (100 $\mathrm{mg} \cdot \mathrm{kg}^{-1}$ compound 1a) and control group (200 mg. $\mathrm{kg}^{-1}$ Inositol Hexanicotinate) respectively.

\section{HFD composition}

HFD was composed with $90.5 \%$ basal diet, $2 \%$ cholesterol, $0.5 \%$ propacil and $7 \%$ grease.

\section{Adiminstration modality}

Drugs were intragastric administration with suspension in olive oil $(0.1 \mathrm{ml} / 10 \mathrm{~g})$ at 9 A.M. The normal group and model group were administered only olive oil. After 4 weeks, animals were fasted overnight. Next day, blood samples were collected fast from the retroorbital sinus into tubes; serum was separated and stored at $-80^{\circ} \mathrm{C}$ until analysis. Then animals were sacrificed by cervical dislocation and tissues were harvested, weighed, snap frozen in liquid nitrogen and stored at $-80^{\circ} \mathrm{C}$ until use. All animal experiments were approved by the Institutional Animal Care and Use Committees of Nanjing Medical University, and followed National Research Council Guidelines.

\section{Biochemical analysis}

In serum, total cholesterol (TC), high density lipoprotein cholesterol (HDL-C), low density lipoprotein cholesterol (LDL-C) and triglyceride (TG) were measured by Automatic Analyzer 7170A (Hitavhi, Jap.). Serum leptin was detected through leptin ELISA kit (Boster, China).

\section{Histological analysis}

The right lobe of rat liver was fixed in 10\% phosphatebuffered formalin for one day and processed in a routine manner to generate $3 \mu \mathrm{m}$ thick paraffin sections, which were stained with hematoxylin and eosin (HE) and subjected to microscopic examination.

\section{Cell culture}

3T3-L1 preadipocytes were cultured in DMEM supplemented with $10 \%$ fetal bovine serum (FBS). After cell reached $80 \%$ confluence, the preadipocytes were induced with $1 \mathrm{mg} \cdot \mathrm{mL}^{-1}$ insulin (Wanbang), $1 \mathrm{mmol} \cdot \mathrm{L}^{-1} \mathrm{DEX}$ (Xianju) and $0.5 \mathrm{mmol} \cdot \mathrm{L}^{-1} \mathrm{MIX}$ (Sigma) (MDI) in DMEM supplemented with $10 \%$ fetal bovine serum. After $48 \mathrm{~h}$, the culture medium was replaced with DMEM supplemented with $10 \%$ fetal bovine serum and $1 \mathrm{mg} \cdot \mathrm{mL}^{-1}$ insu- 
lin, which was switched to DMEM containing $10 \%$ fetal bovine serum 2 days later. Cytoplasmic triglyceride droplets were visible under the fluorescence microscope (Carl Ziess Axiovert $40 \mathrm{CFL}$ ). For the following experiments, preadipocytes and mature adipocytes were treated for 48 h. All compounds, stock solutions were prepared in DMSO and filter sterilized.

\section{Cell Viability}

All the tests were done in 96-well plates. For non-maturing preadipocyte experiments, cells were seeded $\left(5 \times 10^{3}\right.$ cells/well) and grown until they reached confluence, and then treated with the compounds or vehicle (DMSO). After the cells were treated with compound 1a for the 48 $\mathrm{h}$, MTT (Sigma) solution $20 \mu \mathrm{L}\left(0.5 \mathrm{mg} \cdot \mathrm{mL}^{-1}\right)$ was added into the cell culture medium, and the cells were incubated at $37^{\circ} \mathrm{C}$ and $5 \% \mathrm{CO}_{2}$ for $4 \mathrm{~h}$. The MTT formazan crystals were then dissolved with $150 \mu \mathrm{L}$ DMSO and the absorbance in individual wells was determined at $570 \mathrm{~nm}$ by a microplate reader (Labsystems Multiskan Ascent). The inhibition of cell growth was evaluated by the MTT method by using triplicate assay. The inhibition ratio was calculated thorough the formula 1.

Inhibition ratio $=\left(1-\mathrm{OD}_{\text {experimental group }} / \mathrm{OD}_{\text {blank group }}\right) \times 100 \%$

\section{Oil-Red-O staining}

For Oil-Red-O staining [21], cells were washed gently with phosphate buffered saline (PBS) twice, fixed with $3.7 \%$ fresh formaldehyde (Sigma) in PBS for $1 \mathrm{~h}$ at room temperature and stained with filtered Oil-Red-O (Sigma) solution (60\% isopropanol and $40 \%$ water) for at least $1 \mathrm{~h}$. After staining of lipid droplets with red, the Oil-Red-O staining solution was removed and the plates were rinsed with water and dried. Images of the stained lipid droplets were collected on a fluorescence microscope (Carl Ziess Axiovert $40 \mathrm{CFL}$ ). The inhibition ratio of lipid production was calculated through formula 1.

\section{Measurement of the triglyceride content}

Cells were seeded in 96-well plates. 3T3-L1 adipocyte monolayer was washed three times with phosphate-buffered saline (PBS) and then fixed for $30 \mathrm{~min}$ with $3.7 \%$ formaldehyde in PBS. Oil-Red-O $(0.5 \%)$ in isopropanol was diluted with $2 / 3$ volumes of water, filtered and added to the fixed cell monolayer for $1 \mathrm{~h}$ at room temperature. The cell monolayer was then washed with PBS, and the stained triglyceride droplets in the cells were visualized. Finally, the dye retained in the cells was eluted with isopropanol and quantified by measuring the optical absorbance at $492 \mathrm{~nm}$ by a microplate reader (Labsystems Multiskan Ascent). The inhibition of lipid accumulation was evaluated by using triplicate assay.

\section{Apoptosis assays}

\section{Chromatin Staining with Hoechst 33342}

Cells were fixed with $3.7 \%$ para-formaldehyde for $30 \mathrm{~min}$, and then stained with $10 \mu \mathrm{mol} \cdot \mathrm{L}^{-1}$ Hoechst 33342 dye (Sigma) for $30 \mathrm{~min}$ in the dark. After staining, cells were observed by fluorescence microscopy (Carl Ziess Axiovert $40 \mathrm{CFL}$ ). Cells with bright blue fragmented nuclei showing condensation of chromatin were identified as apoptotic cells.

\section{Flow cytometry}

Phosphatidylserine exposed on the outside of the apoptotic cells was determined by anannexin V-fluorescein isothiocyanate (FITC) Apoptosis kit (KeyGene). In brief, to detect early apoptosis, late apoptosis, and necrosis induced by compound 1a, we plated the 3T3-L1 adipocytes at a density of $1 \times 10^{6}$ cells $/$ dish in a $60-\mathrm{mm}$ dish and exposed them for $24 \mathrm{~h}$ at $37^{\circ} \mathrm{C}$. Cells were harvested by centrifugation and washed with ice-cold PBS twice; the cells were then stained with $20 \mu \mathrm{L}$ of annexin V-FITC and $20 \mu \mathrm{L}$ of PI at room temperature for 15 min in the dark. Annexin V-FITC and PI emissions were detected in the FL1 and FL2 channels of a FACScan flow cytometer (BD FACSC anto $\left.{ }^{\mathrm{m}}\right)$, using emission filters of $525 \mathrm{~nm}$ and 575 $\mathrm{nm}$. The percentages of distribution of normal cells and cells in early apoptosis, late apoptosis and necrosis were calculated by CellQuest software (BD Biosciences).

\section{Statistical Analysis}

Data are presented as the mean \pm SD. Data were analyzed by one-way ANOVA using Statistical Package for Social Science (SPSS, Chicago, IL). Differences were considered to be significant at $\mathrm{p}<0.05$.

\section{Results}

\section{Body mass (BM) and fat mass}

After 4 weeks' induction, mice fed with HFD had 5.3\% higher body weights compared with normal group fed with LFD $(\mathrm{p}<0.05)$. The obese model was made successfully. Four-week treatment later, low dosage group and high dosage group had $6.86 \%$ and $12.33 \%$ lower body weights $(\mathrm{p}<0.05)$ than model group respectively (Fig.2A). No obvious difference was found between normal group and high dosage group. As compound 1a dosage doubled, the weight loss compared with model group increased. The weight loss displayed dosage dependence.

White adipose tissue mass was also significantly increased by $148 \%$ in model group compared with normal group ( $<$ 0.05) (Fig.2B). In response to compound $\mathbf{1 a}$ at high dosage, the adipose tissue weights in high dosage group were significantly decreased by $35.29 \%$ compared with the model group $(p<0.05)$. The result inferred that compound 1a inhibited HFD-induced body weight gain and adipose tissue mass in mice effectively. 
A

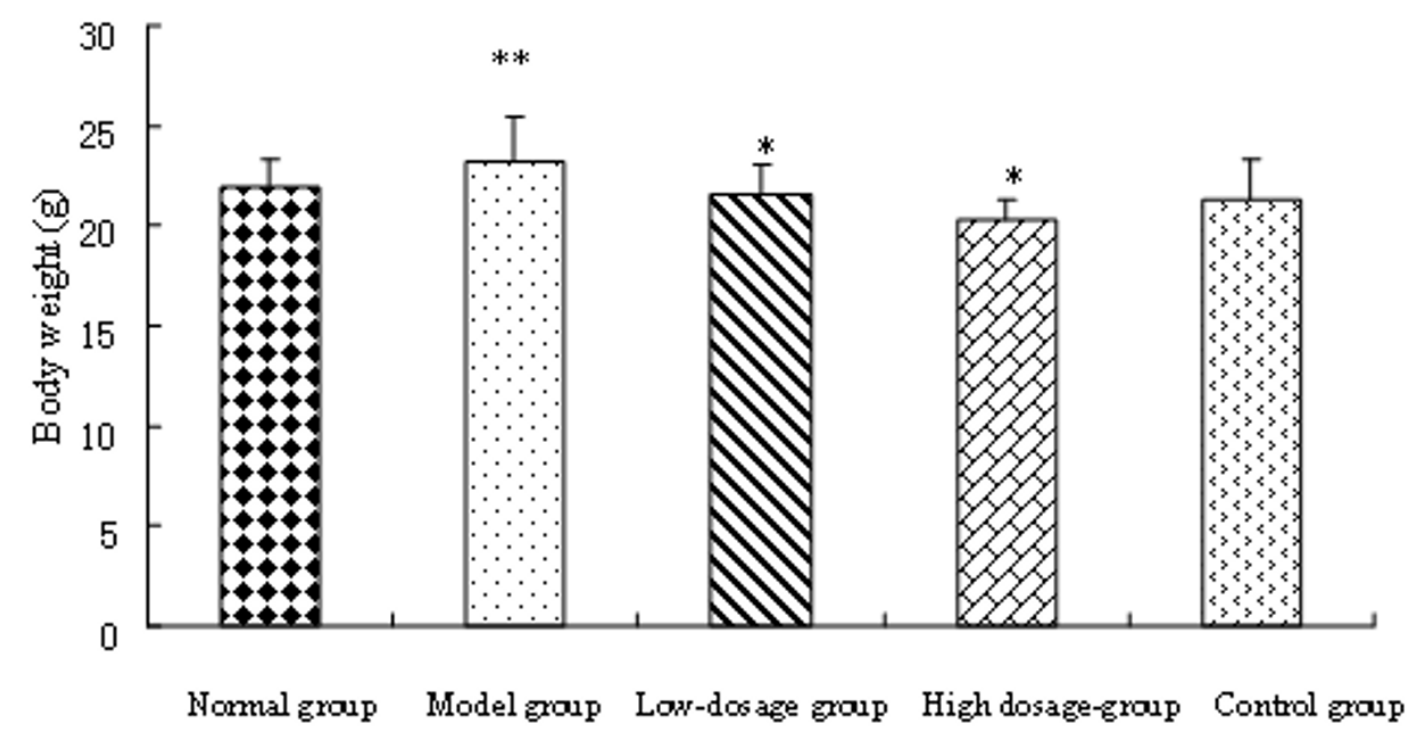

$\mathrm{B}$

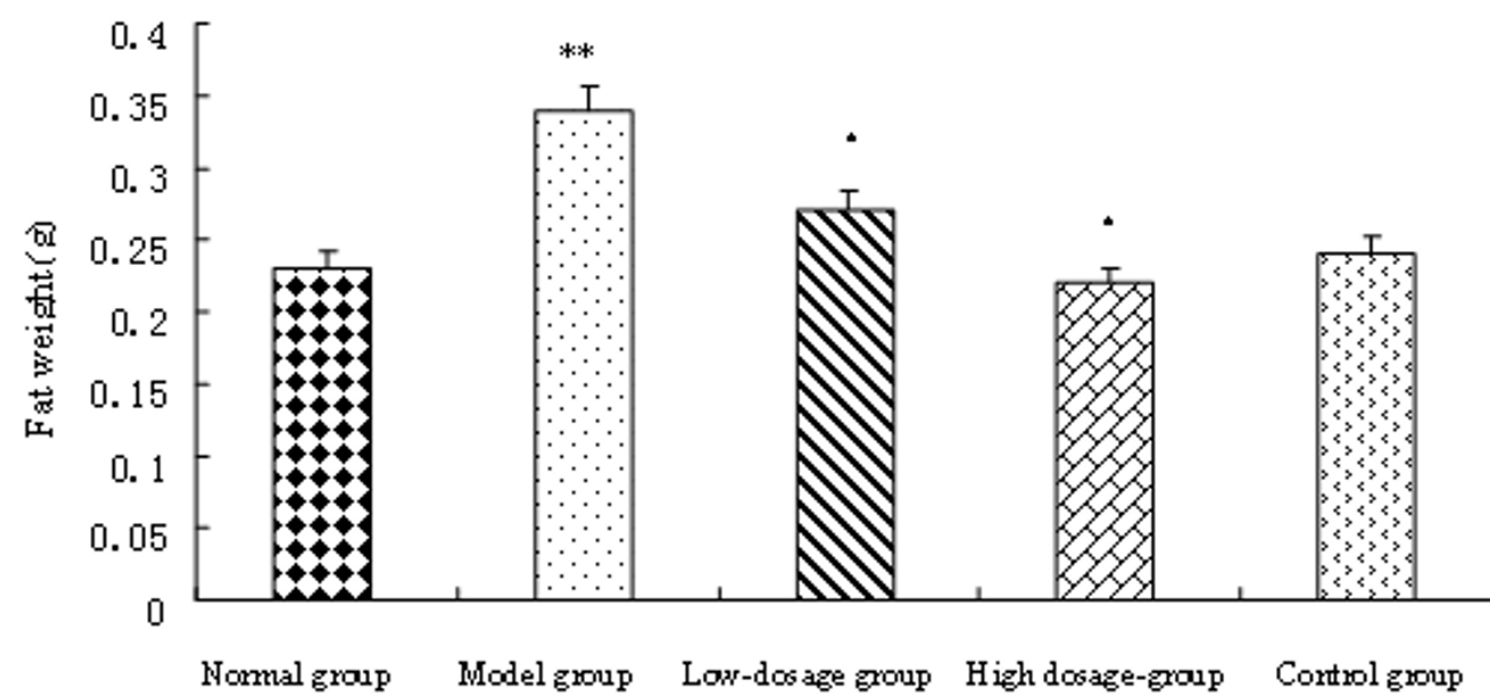

Figure 2 Effects of compound 1a on C57BL/6J mice. A: Effects of compound $\mathbf{1} \mathbf{a}$ on the weight of the mice after treatment. B: Effects of compound $1 \mathbf{a}$ on the weight of the adipose tissue after treatment. Normal group: low fat diet; Model group: high fat diet; Low dosage group: high fat diet+50 $\mathrm{mg} \cdot \mathrm{kg}^{-1}$ compound $\mathbf{1} \mathbf{a}$; High dosage group: high fat diet+100 mg $\mathrm{kg}^{-1}$ compound $\mathbf{1}$; ; Control group: high fat diet+200 mg $\cdot \mathrm{kg}^{-1}$ Inositol Hexanicotinate. All values are mean $\pm S D(n=10)$, ${ }^{*}$ presents $P<0.05$ compared with model group. ${ }^{* *}$ presents $P<0.05$ compared with normal group

\section{Changes in lipid profiles}

To determine whether compound 1a has beneficial effects on the circulating lipid profiles, we tested its effects on serum triglyceride and cholesterol levels. Compared with normal group, serum levels of triglycerides and total cholesterol in model group were increased by $21.32 \%(\mathrm{p}<0.05)$ and $164 \%(\mathrm{p}<0.05)$ respectively
(Fig.3A). This result suggested that the high lipid model was made successfully. After treatment, compound 1a (high dosage) caused significant reductions in serum triglyceride and total cholesterol levels by $28 \%(\mathrm{p}<0.05)$ and $46 \%(\mathrm{p}<0.05)$ respectively, compared with model group. It was worthy noted that serum HDL-C in high dosage group was much higher than that in other groups $(\mathrm{p}<$ 

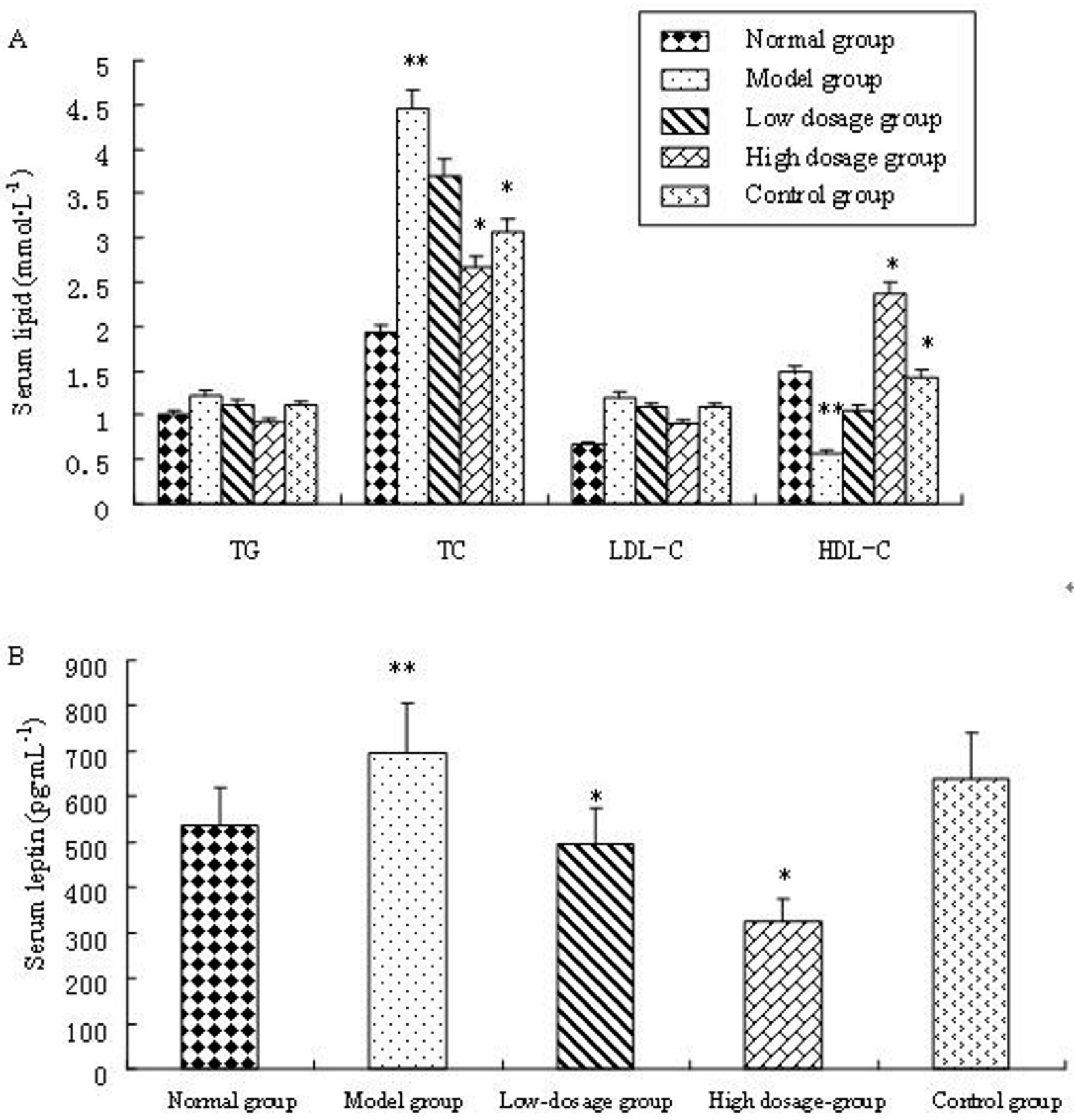

Figure 3 Effects of compound 1a on serum lipids and leptin. A: Changes in TG, TC, LDL-C and HDL-C by compound 1a in high-fat diet fed obese mice. Compound $\mathbf{1 a}$-treated mice had significantly lower serum concentration of triglycerides and higher HDL-C compared with high-fat diet alone. B: Effects of compound $\mathbf{1}$ a on serum leptin. Serum leptin concentration was reduced by compound $\mathbf{1}$ a in a concentration dependent manner. Normal group: low fat diet; Model group: high fat diet; Low dosage group: high fat diet+50 mg $\mathrm{kg}^{-1}$ compound 1a; High dosage group: high fat diet+100 $\mathrm{mg} \cdot \mathrm{kg}^{-1}$ compound $1 \mathrm{a}$; Control group: high fat diet $+200 \mathrm{mg} \mathrm{kg}^{-1}$ Inositol Hexanicotinate. All values are mean \pm SD $(n=10),{ }^{*}$ presents $\mathrm{P}<0.05 \mathrm{com}-$ pared with model group. ${ }^{* *}$ presents $\mathrm{P}<0.05$ compared with normal group.

0.05). Consequently, we believed that compound 1a suppressed lipid disorders through increasing HDL-C and depressing TG, thereby preventing hypertriglyceridemia and hypercholesterolemia.

\section{Changes in serum leptin}

The serum leptin level in model group was much higher than that in normal group $(\mathrm{p}<0.05)$. The result implied that obesity mice accompanied with leptin resistance. 
Compound 1a (high dosage) caused significant reduction in serum leptin by $52.21 \%(\mathrm{p}<0.05)$ compared with model group and reduced serum leptin in a dose- dependent manner (Fig. 3B).

The results suggested that compound 1a could improve leptin resistance induced by obesity.

\section{Hepatic lipid accumulation}

The hepatic accumulation of lipid was observed in mice hepatic tissue slice by light microscopy. Mice in model group showed considerable hepatic lipid accumulation compared with that in normal group.

The mice hepar in high dosage group showed considerably lower hepatic lipid accumulation than in model group. As shown in Fig.4, the triglyceride droplets appeared in mice hepar were almost completely disappeared by compound 1a treatment. Thus, the result suggested that compound 1a could increase fat catabolism in the liver and inhibited hepatic lipid accumulation.

\section{Proliferation and differentiation of 3T3-L1}

To determine whether compound 1a inhibited the cell viability of 3T3-L1 preadipocytes, cells were treated with four various doses of compound 1a and Inositol Hexanicotinate. Cell viability was estimated by the MTT assay and compound 1a treatment inhibited cell growth in a dose-dependent manner (Fig.5). When it reached 0.1 $\mathrm{mmol} \cdot \mathrm{L}^{-1}$, the viability was suppressed by $28.31 \%$. To examine the effect of compound 1a on adipogenesis, 3T3-L1 preadipocytes were treated with adipogenic hormone mixture in the absence or presence of compound 1a. During 3T3-L1 cell differentiation, the number of larger lipid droplets in cells decreased. After 10 days, triglyceride content of 3T3-L1 cells treated with compound 1a was measured. It exhibited a significant dose-dependent decrease in the intracellular accumulation of triacylglycerol under Oil-Red-O staining (Fig.6). However, there was no significant difference between Inositol Hexanicotinate group and the control group.

\section{Apoptosis assays}

An increase in apoptotic nuclei in both preadipocytes and mature adipocytes treated with $0.1 \mathrm{mmol} \cdot \mathrm{L}^{-1} \mathrm{com}$ pound 1a were evident from photos of Hoechst-33342 staining (data not show). We suggested that apoptosis was induced by the compound 1a both in preadipocytes and in mature adipocytes.

To quantify the modes of cell death induced by compound 1a, 3T3-L1 preadipocytes and adipocytes were treated with series concentration of compound $1 \mathbf{a}\left(1 \times 10^{-}\right.$ $\left.{ }^{4}, 1 \times 10^{-5}, 1 \times 10^{-6}, 1 \times 10^{-7} \mathrm{~mol} \cdot \mathrm{L}^{-1}\right)$ for $24 \mathrm{~h}$, were subjected to simultaneous staining with annexin V-FITC and PI, and were analyzed by FACScan flow cytometry. Annexin V-FITC/PI double-staining analysis demon- strated that the number of normal cells decreased in a dose-dependent manner exposed to compound 1a. The apoptotic cells, including early apoptosis and late apoptosis, were increased in a dose-dependent manner. When the compound 1a concentration elevated to $0.1 \mathrm{mmol} \cdot \mathrm{L}^{-1}$, the percentage of cells in G3 decreased from $52.2 \%$ to $35.9 \%$ (preadipocytes) and from $86.1 \%$ to $72 \%$ (adipocytes), respectively; cells in G2 and G4, including early and late apoptosis, increased from $47.8 \%$ to $64.1 \%$ (preadipocytes) and from $13.3 \%$ to $27.4 \%$ (adipocytes), respectively (Table.1, Fig.7).

The result demonstrated that compound 1a could induce apoptosis of both preadipocytes and mature adipocytes.

\section{Discussion}

Obesity is the result of an energy imbalance caused by an increased ratio of caloric intake to energy expenditure. In conjunction with obesity, related metabolic disorders such as dyslipidemia, atherosclerosis, and type 2 diabetes have become global health problems. As well as diet and exercise, some drugs are useful for weight reduction. To date, only sibutramine and orlistat have been approved for use, though both have poor outcomes and are not so well tolerated [22]. Rimonabant is a selective CB1 receptor blocker which has been proven effective in achieving substantial weight loss and in reducing triglyceride levels and glycohemoglobin. It has also been shown to increase HDL cholesterol levels in obese patients and specifically in patients with diabetes [23-25]. However, it was reported that sibutramine, orlistat and Rimonabant had several serious adverse effects in clinic, including gastrointestinal adverse effect and significant unfavorable effects on cardiovascular system. As a result, much safer therapeutic is necessary. In addition, there has been a large increase in the use of complementary treatments such as herbal remedies in the treatment of these diseases over the past decade [26].

We observed that mice fed with HFD supplemented with compound 1a for 4 weeks had lower levels of serum triglycerides, LDL-C and higher levels of HDL-C compared with mice fed with HFD alone, which indicated that compound 1a efficiently regulated triglyceride and cholesterol metabolism in obese mice. Thus, compound 1a may be beneficial for treating patients with hypercholesterolemia and hypertriglyceridemia.

Lipids are transported in the body by a sophisticated lipoprotein transport system. Lipoproteins are divided into 5 main classes according to their density: chylomicrons, VLDL-C, IDL-C, LDL-C and HDL-C [27]. LDL-C is a risk factor for CAD. The antagonist of LDL-C is HDLC. It collects cholesterol from body tissues and returns it to the liver. As a result, HDL-C cholesterol levels are inversely related to this risk [28]. Compound 1a was 

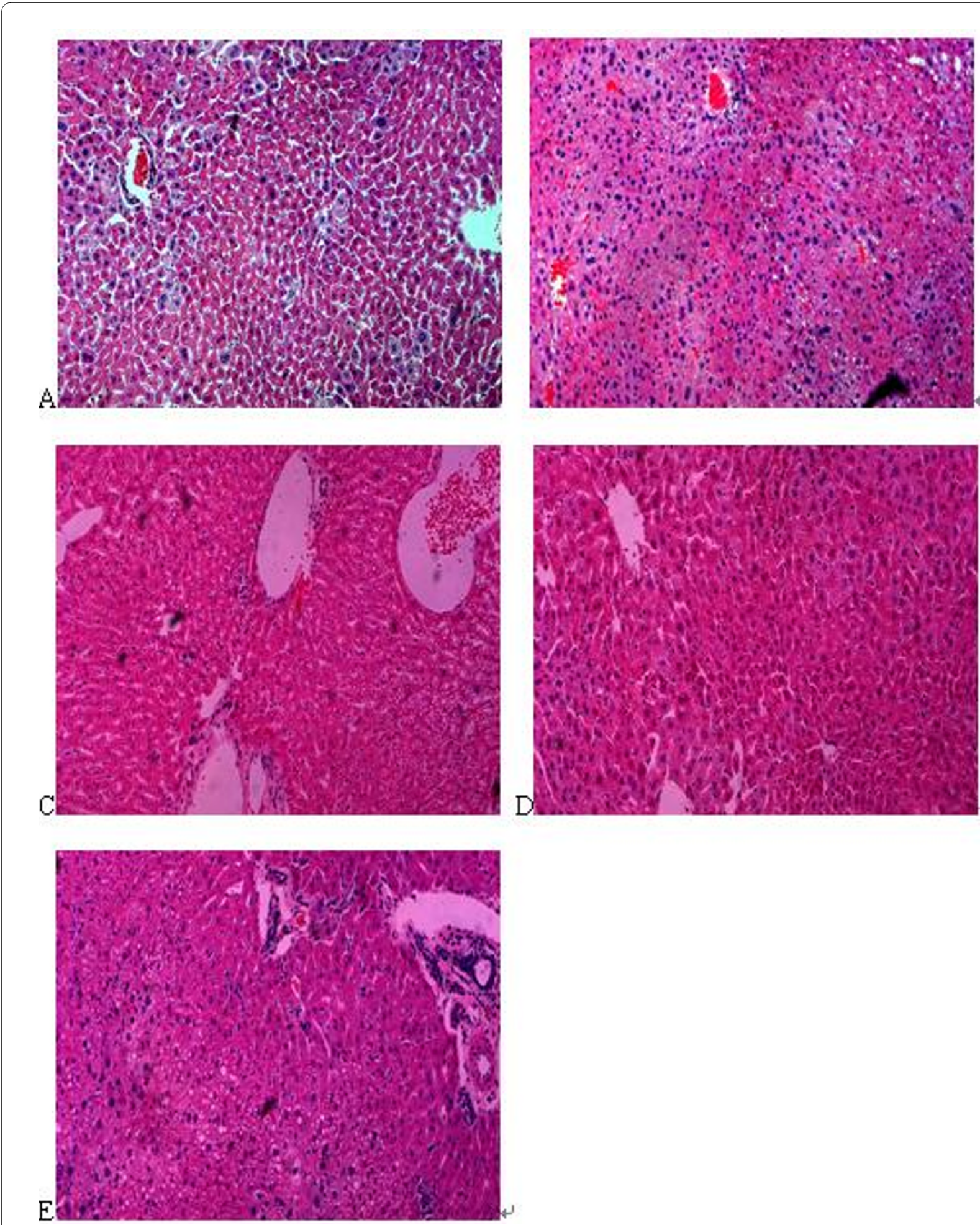

Figure 4 Inhibition of hepatic lipid accumulation by compound 1a in high-fat diet-fed obese mice. Histological analyses of hepatic lipid accumulation. Representative HE-stained liver sections are shown (original magnification 200X). A presents the normal hepatocyte appearance. High fat diet induced hepatocytes necrosis was shown in $\mathbf{B}$. After the treatment of compound $\mathbf{1} \mathbf{a}$, necrosis hepatocytes are reduced, especially in $\mathbf{D}$. Small lipid drops were seen $\mathbf{C}$. There were obvious lipid drops in E. A: low fat diet (normal group); B: high fat diet (model group); $\mathbf{C}$ : high fat diet $+50 \mathrm{mg} \cdot \mathrm{kg}^{-1} \mathrm{Com}-$ pound $\mathbf{1 a}$ (low dosage group); $\mathbf{D}$ : high fat diet+100 $\mathrm{mg} \cdot \mathrm{kg}^{-1}$ compound $\mathbf{1 a}$ (high dosage group); $\mathbf{E}$ : high fat diet+200 mg $\mathrm{kg}^{-1}$ Inositol Hexanicotinate (control group). 


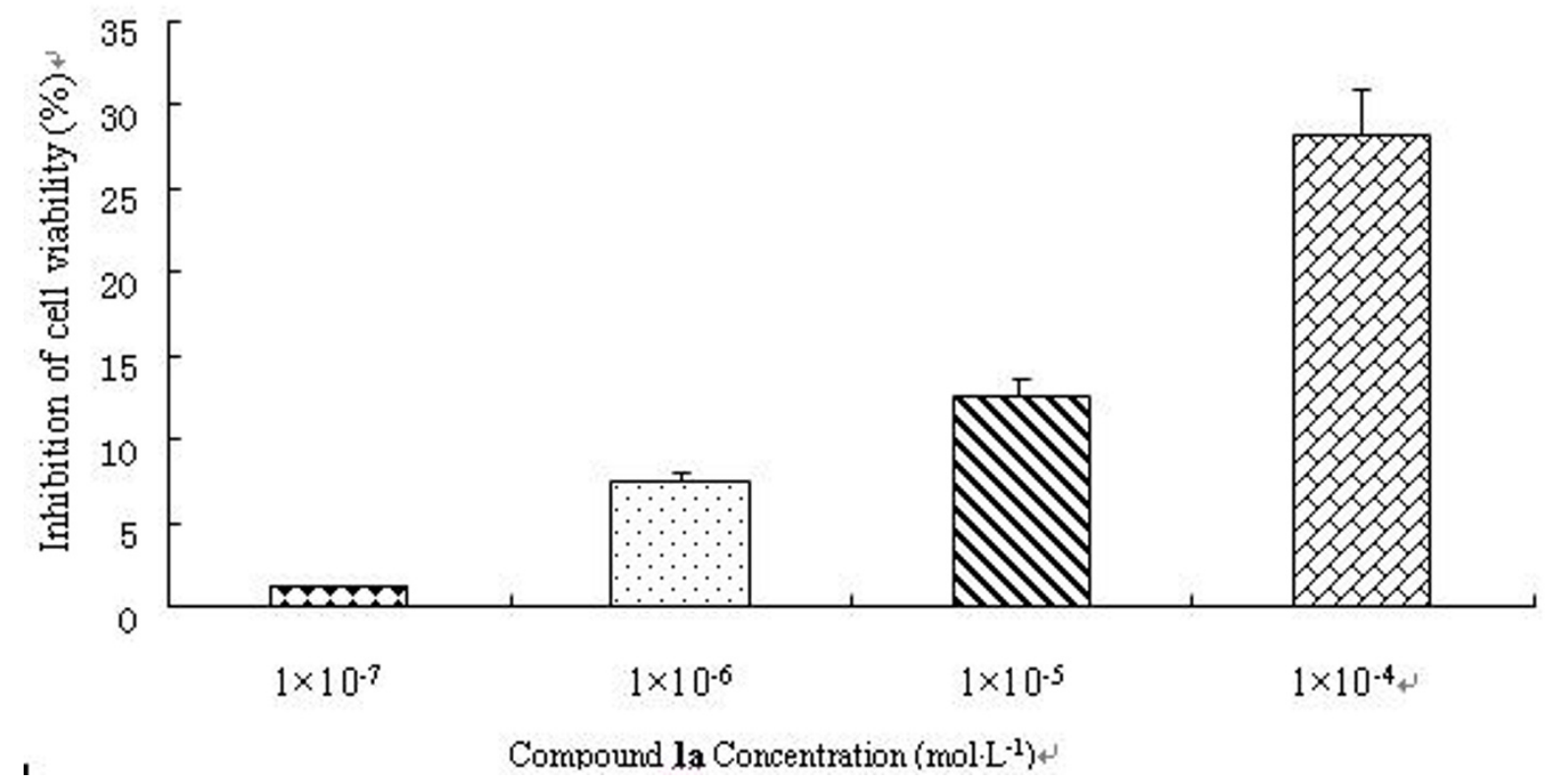

Figure 5 Effect of compound 1a on the inhibition of cell viability in 3T3-L1 preadipocytes. After the influence reached 80\%, 3T3-L1 preadipocytes were incubated with compound $\mathbf{1} \mathbf{a}$, at the indicated concentration $\left(1 \times 10^{-7}, 1 \times 10^{-6}, 1 \times 10^{-5}, 1 \times 10^{-4} \mathrm{~mol} \mathrm{~L}^{-1}\right)$ for $48 \mathrm{~h}$; growth rate was assessed by MTT assay. The inhibition ratio was calculated by formula 1. All values are mean $\pm \operatorname{SD}(n=3)$

determined to effectively in elevating HDL-C. Thus, we tentatively put forward that compound 1a was effective in reversing coronary artery disease.

In parallel with its effect on serum TG, mice fed with HFD supplemented with compound 1a had significantly lower adipose tissue mass and body weight gain than that fed with HFD alone. This correlated with reports showed that the lipids in adipose tissue were largely derived from circulating triglycerides, especially during HFD feeding $[29,30]$ and that the reductions in serum TG also led to decreased adipose tissue mass [31-33].

Increased lipid accumulation in hyperlipidemic rats and mice may be due to increased levels of triglyceride depots in the liver [33]. Histological analysis in our research showed that HFD-fed mice had considerable hepatic lipid accumulation. After 4-week treatment with compound 1a, hepatic lipid accumulation disappeared (high dosage group). Long term hepatic lipid accumulation would cause fatty liver. Thus the result suggested that compound 1a could recover fatty liver induced by lipid accumulation.

Leptin, a 167-amino acid protein, is synthesized and secreted mainly by adipose tissue $[34,35]$. Adipose tissue produces the hormone leptin in approximate proportion to fat stores. Circulating leptin communicates the level of energy reserves in the periphery to the central nervous system (CNS) in order to suppress food intake and permit energy expenditure [34,36-38]. Peripheral administration of exogenous leptin results in a specific reduction in body fat mass with no change in lean mass in experimental animals [39] or in obese humans on a weight-reducing diet [40], but elevated concentrations of endogenous leptin do not appear to be capable of preventing, or reversing, the accumulation of adipose tissue during, or after, the development of obesity [41]. Several authors have reported that aging $[42,43]$ or the consumption of a HFD [44-46] results in the development of leptin resistance in rodents, measured as a failure of leptin either to inhibit food intake or to induce weight loss. Increased circulating leptin, a marker of leptin resistance, is common in obesity and independently associates with insulin resistance [47] and CVD [48-51] in humans. In our study, Serum leptin in model group was raised during the induction of HFD to $694.76 \mathrm{pg} \cdot \mathrm{mL}^{-1}$. After the treatment of $100 \mathrm{mg} \cdot \mathrm{kg}^{-1}$ compound 1a, the serum leptin was reduced to $52.21 \%$ compared with model group. It suggested that compound 1a was effective to leptin resistance induced by HFD in mice.

The possible mechanisms for the treatment of obesity are as follows: balance energy intake and expenditure, reduce preadipocyte differentiation, decrease lipogenesis, increase lipolysis and induce adipocyte apoptosis [52]. Adipocytes play an important role in lipid homeostasis and energy balance by relating to triglyceride storage and 


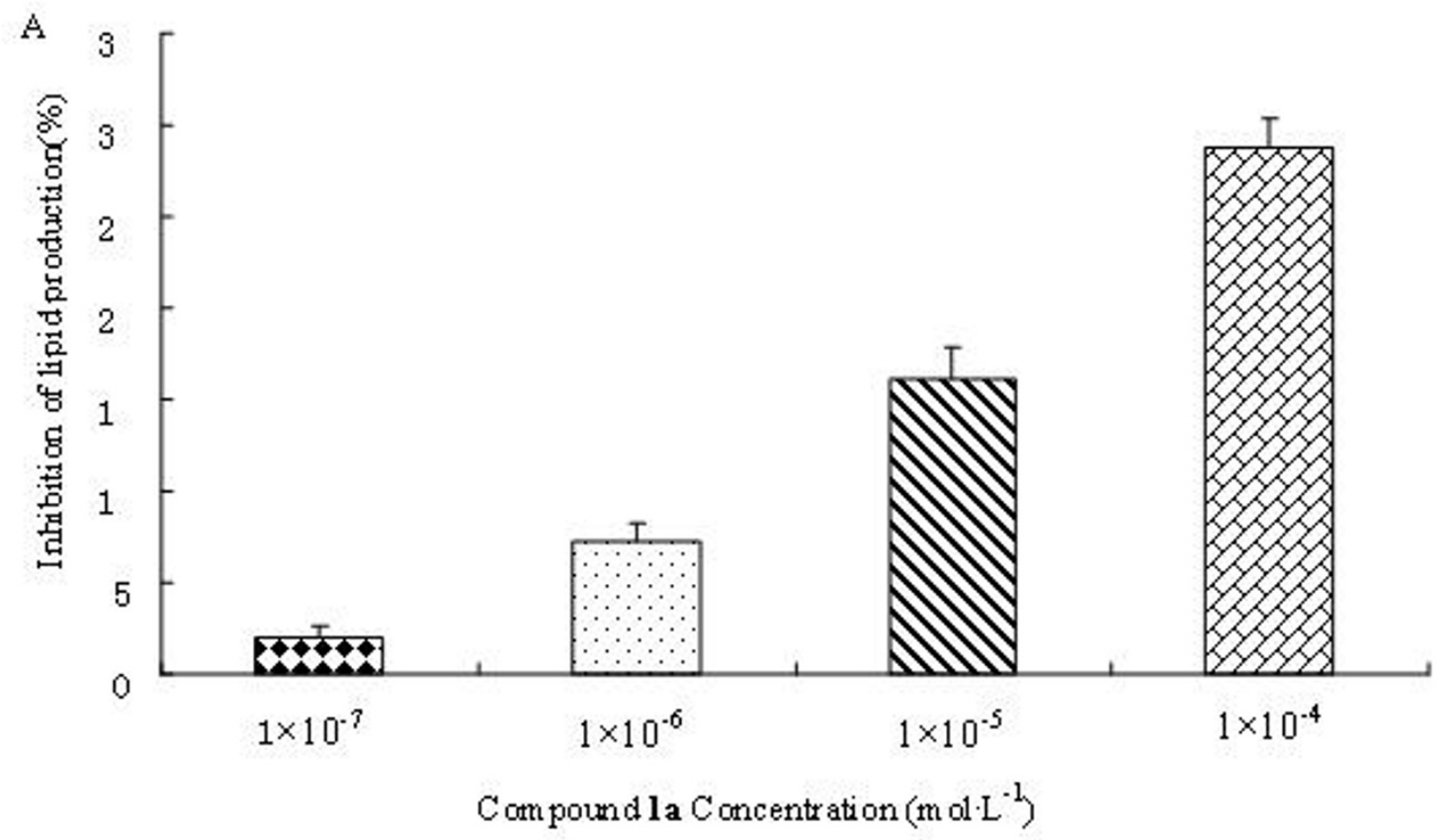

$\mathrm{B}$

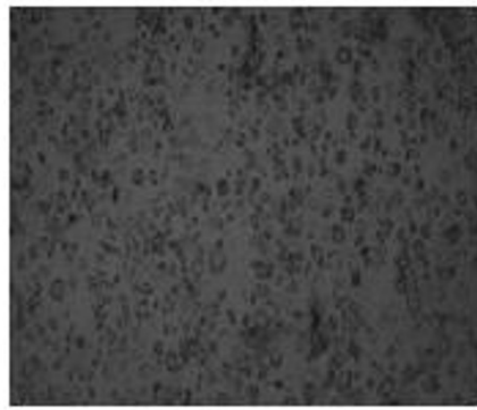

DMSO

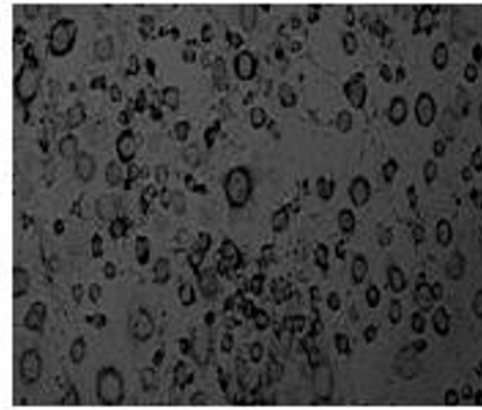

compound la

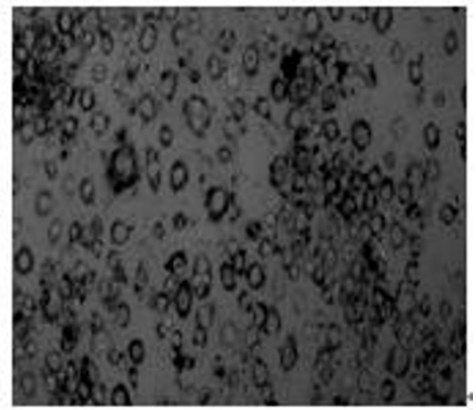

Inositol Hexanicotinate

Figure 6 Effect of compound 1a on lipid adipogenesis. A: Effect of compound 1a on lipid accumulation in 3T3-L1 adipocytes. At two days after confluence, 3T3-L1 cells were differentiated by MDI. At day 8 compound 1a was given to the cells at series of concentrations. Ten days after differentiation, we measured triglyceride content of 3T3-L1 cells treated with compound 1a by Oil-Red-O staining. The inhibition ratio was calculated by formula 1. B: Effect of vehicle, compound 1a, Inositol Nicotinate on the lipid accumulation by Oil-Red-O staining. Images of the stained lipid droplets were collected on a fluorescence microscope. Lipid accumulation was significantly decreased treated by compound $\mathbf{1} \mathbf{a}$. All values are mean \pm SD ( $\mathrm{n}$ $=3$ ).

free fatty acids release. Adipocyte differentiation and the amount of fat accumulation are associated with the occurrence and development of obesity [53]. Moreover, adipocyte produces and secretes dozens of factors such as leptin, adiponectin, resistin, visfatin, TNF- $\alpha$, and IL-6, which participate in energy metabolism of adipose tissue itself and the whole body either in an auto/paracrine or an endocrine fashion [54]. For these reasons, anti-obesity works have been conducted in 3T3-L1 adipocytes.
Anti-obesity effect of compound 1a in the 3T3-L1 cell model was measured in our study. Any reduction in adipocyte number can result from preadipocyte or adipocyte apoptosis, as well as adipocyte dedifferentiation [55]. In this study we investigated the effects of compound 1a on adipocyte viability, apoptosis and lipid accumulation during adipogenesis in 3T3-L1 cells. We found that compound 1a inhibited cell viability and enhanced apoptosis in both pre- and mature adipocytes. Correspondingly, the 
Table 1: Preadipocytes(table.1-1) and mature adipocytes(table.1-2) were incubated in vitro without or with $1 \times 10^{-7}, 1 \times$ $10^{-6}, 1 \times 10^{-5}, 1 \times 10^{-4} \mathrm{~mol} \cdot \mathrm{L}^{-1}$ of compound $1 \mathrm{a}$ for $24 \mathrm{~h}$ and analyzed by Annexin V/PI cell viability assay.

\begin{tabular}{cccccc}
\hline \multicolumn{1}{c}{$\mathbf{1 - 1}$} & & & \\
\hline \%Parent & blank & $\mathbf{1 * 1 0 - 7}$ & $\mathbf{1 * 1 0 - 6}$ & $\mathbf{1 * 1 0 - 5}$ & 1.5 \\
\hline Q1 & 1.7 & 2.5 & 3.8 & 41.6 & 43.2 \\
\hline Q2 & 39.0 & 38.5 & 39.2 & 39.5 & 34.4 \\
\hline Q3 & 50.5 & 47.6 & 46.7 & 16.0 & 20.9 \\
\hline
\end{tabular}

$1-2$

\begin{tabular}{cccccc}
\hline Q1 & 0.5 & 0.2 & 0.5 & 0.1 & 0.5 \\
\hline Q2 & 1.8 & 1.3 & 1.5 & 1.4 & 2.7 \\
\hline Q3 & 86.1 & 85.8 & 85.4 & 81.2 & 72 \\
\hline Q4 & 11.5 & 12.8 & 12.6 & 17.3 & 24.7 \\
\hline
\end{tabular}

Apoptotic (Q4+Q2) cells were identified and expressed as a percentage of total dead cells.

lipid accumulation was suppressed during the differentiation process. As to in vivo experiment, the adipose was depauperated, which was coincident with the weight and adipose tissue loss.

Lipolysis is a property of mature, differentiated adipocytes. Adipocyte maturation requires an elaborate sequence of events associated with specific patterns of

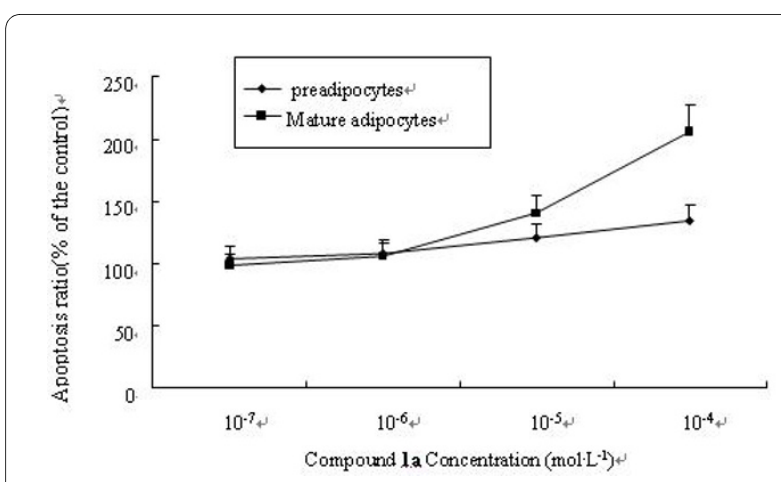

Figure 7 Apoptosis ratios (apoptosis cell number in treatment group/apoptosis cell number in blank group) after $24 \mathrm{~h}$ were shown in this picture. With the concentration increase, the apoptosis ratio was raised both in preadipocytes and mature adipocytes. The phenomenon was more notable in mature adipocytes induced by $1 \times$ $10^{-4} \mathrm{~mol}^{\mathrm{L}-1}$ compound $\mathbf{1} \mathbf{a}$, whose apoptosis ratio reached almost 206\% compared with DMSO group. transcription factors at different phases of differentiation [56]. Mature adipocytes have massive TG storage compared with any other tissue, despite having a well-developed lipolytic capacity. Conversely, a decrease of adipocyte differentiation, which by definition is associated with reduction of the lipid droplet volume, will transiently be accompanied by a net increase in lipolysis, and this is one potential mechanism for increasing lipolysis. As an important component in the network of lipid energy metabolism, adipocyte lipolysis is positioned to affect the fat content of liver, muscle, heart and kidney in obesity.

In conclusion, the results of the in vivo and in vitro study show that compound $\mathbf{1}$ a regulates serum lipid profiles, decreases adipose tissue mass and body weight gain by inducing adipocyte apoptosis. The compound 1a may be used to treat obese patients with hypercholesterolemia and hypertriglyceridemia. The adipocyte apoptosis mechanism induced by compound $\mathbf{1 a}$ will be further researched.

\section{Abbreviations}

CAD: Coronary Artery Disease; CNS: Central nervous system; CVD: Cardiovascular disease; DEX: Dexamethasone; DMEM: Dulbecco's modified Eagle's medium; FBS: Fetal bovine serum; HFD: High fat diet; HDL-C: High density lipoprotein cholesterol; HE: Hematoxylin and eosin; IBMX: 3-Isobutyl-1-methylxanthine; IL-6: Interleukin-6; LDL-C: Low density lipoprotein cholesterol; LFD: Low fat diet; MTT: 3-(4, 5-Dimethylthiazol-2-yl)-2, 5-diphenyltetrazolium bromide; 
PBS: Phosphate buffered saline; TC: Total cholesterol; TG: Triglyceride; TNF-a: Tumor necrosis factor-a.

\section{Competing interests}

The authors declare that they have no competing interests.

\section{Authors' contributions}

YY carried out both in vivo and in vitro studies and drafted the manuscript. LXB participated in vivo study and helped to draft the manuscript. ZW carried out the synthesis of compound 1a. ZYY cultured the cells. SH carried out the determination of plasma leptin and data analysis. $\mathrm{XH}$ and $\mathrm{XH}$ conceived, design the research. All authors have read and approved the final manuscript.

\section{Acknowledgements}

The authors thank department of Medical Chemistry in China Pharmaceutical University for their assistance in the preparations of the compound $\mathbf{1 a}$.

\section{Author Details}

1Nanjing Brain Hospital affiliated to Nanjing Medical University, Nanjing 210029, PR China, 2Department of Pharmacy English, China Pharmaceutical University, Nanjing 210009, PR China and '3epartment of Medical Chemistry, China Pharmaceutical University, Nanjing 210009, PR China

Received: 11 March 2010 Accepted: 19 May 2010

Published: 19 May 2010

\section{References}

1. Formiguera $X$, Canton A: Obesity: epidemiology and clinical aspects. Best Pract Res Clin Gastroenterol 2004, 18:1125-1146.

2. Grundy SM: Obesity, metabolic syndrome, and cardiovascular disease. J Clin Endocrinol, Metab 2004, 89:2595-2600.

3. Kim HK, Nelson-Dooley C, Della-Fera MA, Yang JY, Zhang W, Duan J, Hartzell DL, Hamrick MW, Baile CA: Genistein decreases food intake, body weight, and fat pad weight and causes adipose tissue apoptosis in ovariectomized female mice. J Nutr 2006, 136:409-414.

4. Vettor R, Rossato M: The blockade of the endocannabinoid CB1 receptors and its influence on cardiometabolic risk: Lesson from Rimonabant In Obesity (RIO) trials. International Congress Series 2007, 1303:146-154

5. Padwal R S, Majumdar S R: Drug treatments for obesity: orlistat, sibutramine, and rimonabant. Lancet 2007, 369:71-77.

6. Sayin T, Güldal M: Sibutramine: Possible cause of a reversible cardiomyopathy. International Journal of Cardiology 2005, 99:481-482.

7. Lin J, Della-Fera MA, Baile CA: Green tea polyphenol epigallocatechin gallate inhibits adipogenesis and induces apoptosis in 3T3-L1 adipocytes. Obes Res 2005, 13:982-990.

8. Xie L, O'Reilly C P: Adiponectin and leptin are secreted through distinct trafficking pathways in adipocytes. Biochimica et Biophysica Acta 2008, 1782:99-108.

9. Fasshauer M, Kralisch S: Adiponectin gene expression and secretion is inhibited by interleukin- 6 in 3T3-L1 adipocytes. Biochemical and Biophysical Research Communications 2003, 301:1045-1050.

10. Araki S, Dobashi K: N-acetylcysteine attenuates TNF-a induced changes in secretion of interleukin-6, plasminogen activator inhibitor-1 and adiponectin from 3T3-L1 adipocytes. Life Sciences 2006, 79:2405-2412.

11. Tanaka Masaki, Nozaki Maiko: Visfatin is released from 3T3-L1 adipocytes via a non-classical pathway. Biochemical and Biophysical Research Communications 2007, 359:194-201.

12. Hargrave KM, Meyer BJ, Li C, Azain MJ, Baile CA, Miner JL: Influence of dietary conjugated linoleic Acid and fat source on body fat and apoptosis in mice. Obes Res 2004, 12:1435-1444.

13. Kim OK: Ginseng saponin-Re and Coix lachrymajobi var. mayuen regulate obesity related genes expressions, TNF-alpha, leptin, lipoprotein lipase and resistin in 3T3-L1 adipocytes. Korean J Life SCi 2007, 17:1523-1532

14. Cho EJ, Rahman A, Kim SW, Baek YM, Hwang HJ, Oh JY, Hwang HS, Lee SH, Yun JW: Chitosan oligosaccharides inhibit adipogenesis in 3T3-L1 adipocytes. J Microbiol Biotechnol 2008, 18:80-87.

15. Tang QQ, Otto TC, Lane MD: Mitotic clonal expansion: a synchronous process required for adipogenesis. Proc Natl Acad Sci USA 2003, 100:44-49.
16. Saltiel AR, Kahn CR: Insulin signaling and the regulation of glucose and lipid metabolism. Nature 2001, 414:799-806

17. Cederroth CR, Nef S: Soy, phytoestrogens and metabolism: A review. Mol Cell Endocrinol 2009, 304(1-2):30-42.

18. Song WO, Chun OK, Hwang I, Shin HS, Kim BG, Kim KS, Lee SY, Shin D, Lee SG: Soy Isoflavones as Safe Functional Ingredients. J Med Food 2007 10:571-580.

19. Veitch NC: Isoflavonoids of the Leguminosae. Nat Prod Rep 2007 24:417-464

20. Ørgaard A, Jensen L: The Effects of Soy Isoflavones on Obesity. Exp Bio Med 2008, 233:1066-1080

21. Havel PJ: Role of adipose tissue in body-weight regulation: mechanisms regulating leptin production and energy balance. Proc Nutr Soc 2000, 59:359-371.

22. Jason CG, Halford: Pharmacotherapy for obesity. Appetite 2006, 46:6-10.

23. Scheen AJ, Finer N, Hollander P, Jensen MD, van Gaal LF: Efficacy and tolerability of rimonabant in overweight or obese patient with type 2 diabetes: a randomized controlled study. Lancet 2006, 368:1660-1672.

24. Christensen R, Kristensen PK, Bartels EM, Bliddal H, Astrup A: Efficacy and safety of the weight-loss drug rimonabant: a metaanalysis of randomised trials. Lancet 2007, 370:1706-1713.

25. Levy P, Fried M, Santini F, Fines: The comparative effects of bariatric surgery on weight and type 2 diabetes. Obes Surg 2007, 17:1248-1256.

26. Ono $Y$, Hattor $E$ : Anti-obesity effect of Nelumbo nucifera leaves extract in mice and rats. Journal of Ethnopharmacology 2006, 106:238-244.

27. Schittmayer M, Birner-Gruenberger R: Functional proteomics in lipid research: Lipases, lipid droplets and lipoproteins. Proteomics 2009

28. Rezaee F, Casetta B: Proteomic analysis of high-density lipoprotein. Proteomics 2006, 2:721-730.

29. Lupien P, Brun D, Gagne C, Moorjani S, Bielman P, Julien P: Gemfibrozi therapy in primary type II hyperlipoproteinemia: effects on lipids, lipoproteins and apolipoproteins. The Canadian Journal of Cardiology 1991, 7:27-33.

30. Fruchart JC, Brewer HB Jr, Leitersdorf E: Consensus for the use of fibrates in the treatment of dyslipoproteinemia and coronary heart disease. Fibrate Consensus Group. The American Journal of Cardiology 1998, 81:912-917

31. Yoon M, Jeong S, Nicol CJ, Lee H, Han M, Kim JJ, Seo YJ, Ryu C, Oh GT: Fenofibrate regulates obesity and lipid metabolism with sexual dimorphism. Experimental and Molecular Medicine 2002, 34:485-492.

32. Yoon M, Jeong S, Lee H, Han M, Kang JH, Kim EY, Kim M, Oh GT: Fenofibrate improves lipid metabolism and obesity in ovariectomized LDL receptor-null mice. Biochemical and Biophysical Research Communications 2003, 302:29-34.

33. Jeong S, Han M, Lee H, Kim M, Nicol CJ, Kim BH, Choi JH, Oh GT, Yoon M: Effects of fenofibrate on high fat diet-induced body weight gain and adiposity in female C57BL/6J mice. Metabolism 2004, 53:1284-1289.

34. Friedman JM, Halas JL: Leptin and the regulation of body weight in mammals. Nature 1998, 395:763-770.

35. Margetic S, Gazzola C, Pegg GG, Hill RA: Leptin: a review of its peripheral actions and interactions. Int J obes Relat, Metab Disord 2002, 26:1407-1433.

36. Elmquist JK, Coppari R, Balthasar N, Ichinose M, Lowell BB: Identifying hypothalamic pathways controlling food intake, body weight, and glucose homeostasis. J Comp Neurol 2005, 493:63-71.

37. Morton GJ, Cummings DE, Baskin DG, Barsh GS, Schwartz MW: Central nervous system control of food intake and body weight. Nature 2006 , 443:289-295.

38. Bates SH, Myers MG Jr: The role of leptin receptor signaling in feeding and neuroendocrine function. Trends Endocrinol Metab 2003, $14: 447-452$

39. Chen $Y$, Heiman M: Chronic leptin administration promotes lipid utilization until fat mass is greatly reduced and preserves lean mass of normal female rats. Regul Pept 2000, 92:113-119.

40. Heymsfield SB, Greenberg AS, Fujioka K, Dixon RM, Kushner R, Hunt T: Recombinant leptin for weight loss in obese and lean adults: a randomized, controlled, dose-escalation trial. JAMA 1999, 282:1568-1575.

41. Considine RV, Caro JF: Leptin and the regulation of body weight. Int J Biochem Cell Biol 1997, 29:1255-1272. 
42. Jacobson L: Middle-aged C57BL/6 mice have impaired responses to leptin that are not improved by calorie restriction. Am J Physiol 2002, 282:E786-793.

43. Scarpace PJ, Matheny M, Zhang Y, Tumer N, Frase CD, Shek EW: Central leptin gene delivery evokes persistent leptin signal transduction in young and aged-obese rats but physiological responses become attenuated over time in aged-obese rats. Neuropharmacology 2002, 42:548-561

44. El-Haschimi K, Pierroz DD, Hileman SM, Bjorbaek C, Flier JS: Two defects contribute to hypothalamic leptin resistance in mice with dietinduced obesity. J Clin Invest 2000, 105:1827-1832.

45. Lin L, Martin R, Schaffhauser AO, York DA: Acute changes in the response to peripheral leptin with alteration in the diet composition. $\mathrm{Am} J$ Physio/ 2001, 280:504-509.

46. Lin S, Thomas TC, Storlien LH, Huang XF: Development of high fat dietinduced obesity and leptin resistance in C57BI/6J mice. Int J Obes Relat Metab Disord 2000, 24:639-646.

47. Mantzoros CS, Liolios AD, Tritos NA: Circulating insulin concentrations, smoking, and alcohol intake are important independent predictors of leptin in young healthy men. Obes Res 1998, 6:179-186.

48. Soderberg S, Ahren B, Jansson JH: Leptin is associated with increased risk of myocardial infarction. J Intern Med 1999, 246:409-418.

49. Wallace AM, McMahon AD, Packard CJ: Plasma leptin and the risk of cardiovascular disease in the west of Scotland coronary prevention study (WOSCOPS). Circulation 2001, 104:3052-3056.

50. Wolk R, Berger P, Lennon RJ, Brilakis ES, Johnson BD, Somers VK: Plasma leptin and prognosis in patients with established coronary atherosclerosis. J Am Coll Cardiol 2004, 44:1819-1824.

51. Reilly MP, lqbal N, Schutta M: Plasma leptin levels are associated with coronary atherosclerosis in type 2 diabetes. J Clin Endocrinol Meta 2004, 89:3872-3878

52. Evans $M$, Lin X, Odle J, McIntosh M: Trans-10, cis-12 conjugated linoleic acid increases fatty acid oxidation in 3T3-L1 preadipocytes. J Nutr 2002, 132:450-455

53. Jeon T, Hwang SG, Hirai S, Matsui T, Yano H, Kawada T, Lim BO, Park DK: Red yeast rice extracts suppress adipogenesis by down-regulating adipogenic transcription factors and gene expression in 3T3-L1 cells. Life Sci 2004, 17:3195-3203.

54. Zou C, Shao J: Role of adipocytokines in obesity-associated insulin resistance. Journal of Nutritional Biochemistry 2008, 19:277-286.

55. Prins JB, O'Rahilly S: Regulation of adipose cell number in mature adipocytes. Clin Sci (Lond) 1997, 92:3-11.

56. Farme SR: Transcriptional control of adipocyte formation. Cell Metab 2006, 4:263-273

\section{doi: 10.1186/1476-511X-9-49}

Cite this article as: Yao et al., Anti-obesity effect of an isoflavone fatty acid ester on obese mice induced by high fat diet and its potential mechanism Lipids in Health and Disease 2010, 9:49

\section{Submit your next manuscript to BioMed Centra} and take full advantage of:

- Convenient online submission

- Thorough peer review

- No space constraints or color figure charges

- Immediate publication on acceptance

- Inclusion in PubMed, CAS, Scopus and Google Scholar

- Research which is freely available for redistribution

Submit your manuscript at www.biomedcentral.com/submit
C BioMed Central 